Article

\title{
Runner Lifting-Up during Load Rejection Transients of a Kaplan Turbine: Flow Mechanism and Solution
}

\author{
Ke Liu ${ }^{1}$, Feng Yang ${ }^{2}$, Zhiyan Yang ${ }^{1}$, Yunxian Zhu ${ }^{2}$ and Yongguang Cheng ${ }^{1, *}$ \\ 1 State Key Laboratory of Water Resources and Hydropower Engineering Science, Wuhan University, \\ Wuhan 430072, China; liukeyf@whu.edu.cn (K.L.); mry@whu.edu.cn (Z.Y.) \\ 2 Construction Management Company for Chushandian Reservoir Project of Henan Province, \\ Zhengzhou 450000, China; yf2787@163.com (F.Y.); zyx@hnsl.gov.cn (Y.Z.) \\ * Correspondence: ygcheng@whu.edu.cn; Tel.: +86-68772274
}

Received: 18 October 2019; Accepted: 12 December 2019; Published: 15 December 2019

check for updates

\begin{abstract}
Dangerous runner lifting-up (RLU) accidents regarding Kaplan turbines, which are widely used in low-head hydropower stations, were frequently reported. Three-dimensional (3D) computational fluid dynamics (CFD) was used to simulate the load rejection transients with guide-vane closing to predict the RLU possibility of the fixed-blade Kaplan turbine in an under-construction hydropower station. It was found that using any linear closing rule, the upward axial water force on the runner was larger than the weight of rotating parts that started before the guide-vanes were closed, which indicated a RLU possibility. It was the pumping effect that caused the imbalance, during which the high rotational speed runner propels water downstream with a low discharge. We proposed a piecewise closing rule based on this finding. By keeping the opening unchanged in a period in the closing process, the rotational speed can be reduced by using the braking effect, and the concurrence of high speed and low discharge can be prevented. Simulations verified this effective measure and accepted by the manufacturer. Although this study used a fixed-blade Kaplan turbine, the revealed mechanism and verified solution to the RLU problem have reference value for all of the Kaplan turbines.
\end{abstract}

Keywords: Kaplan turbine; load rejection transients; runner lifting-up; CFD simulation; flow patterns

\section{Introduction}

Kaplan turbines are widely used in low-head hydropower stations, because of their high specific-speed, large discharge capacity, and broad performance zone. The setting-elevations of Kaplan turbines are normally lower due to relative larger cavitation coefficient, which results in larger upward tailwater pressure. During load rejection transient process, which is an emergent shut-down with rapid closure of guide-vanes due to grid or generator problems, the runner lifting-up (RLU) accident might happen if the upward axial water force is larger than the weight of the rotating parts of the turbine-generator unit.

RLU accidents about Kaplan turbines were frequently reported, in which serious damage and property losses were accompanied [1-6]. In Kahovskaya Hydroelectric Plant, Russia, a RLU accident happened and the runner blades were damaged due to the large rejoining force after water column separation during a shut-down transient process [1]. Similar RLU accidents that were caused by reverse water hammer also occurred in Stuguns and Akkats power stations [2], Sweden, in which whole shaft lifting and blades breaking were reported. In China, the Kaplan turbines in Hejiatan [3], Mantianxing [4], and Xiacheng [5] hydropower stations encountered several RLU accidents during load rejection transient processes, which resulted in the destruction of the bearings. Twenty-four RLUs 
were recorded within the past ten years in Tishrin hydropower station, Syria, causing great damage to the units [6].

RLUs occur in transient processes, especially the load rejection transient process, during which fast guide-vane closing can cause large water hammer fluctuations in the draft-tube of Kaplan turbines. Many researches on the load rejection transient process of the Kaplan turbines and RLU reasons have been conducted. Chang [7] theoretically analyzed the control mode of Kaplan turbines in transient processes and proposed closing guide-vanes in stages and turn blades to the maximum angle before reaching the maximum speed after load rejection, which has been proven to be reliable and effective to improving stability of transient processes by field practice. Cai et al. [8] theoretically analyzed the RLU reasons of Kaplan turbines, classified the RLU problems into lifting-up by reverse water hammer and by the pumping effect, and put forward several measures to prevent the RLU problems. Yang et al. [9] reported two RLU problems that are caused by the reverse water hammer and pumping effect, respectively, and then analyzed the changing rules of macro-parameters. The reverse water hammer that caused RLU can be described, as follows: during the load rejection transient process, the rapid closure of guide-vanes causes pressure drop in the draft-tube; the water column can be separated if the pressure at the runner outlet reaches at the cavitation pressure [10]; the rejoining of the separated water columns results in an impact on the runner [11]. On the other hand, the pumping effect that caused RLU can be described, as follows: without reverse water hammer during the load rejection transient process, the rotational speed increases while the discharge decreases; the turbine will work in a special mode in which the runner propels water downstream if a high rotational speed encounters a low discharge; if the reaction force of water is large enough the runner can be lifted up. Pejovic [12] gave a formula for predicting water column separation in draft-tube, which considered guide-vane closing time, discharge, tailrace tunnel length, and suction head. Yang et al. [9] investigated the RLU process of a Kaplan turbine, combining theoretical analysis with engineering tests, and proposed a formula for estimating the lifting force of pumping effect, which is related to the diameter and rotational speed of the Kaplan turbine. Min [6] analyzed the causes of RLU of a Kaplan turbine, and solved the problem of RLUs while using the methods, which had not been solved in the power station for nearly ten years. The above studies provided many valuable data and measures, however the in-depth analysis of RLU mechanism of Kaplan turbines is still absent.

Theoretical analysis, engineering tests, and numerical simulations are all useful tools in studying the RLUs of Kaplan turbines. Apart from the aforementioned theoretical and simple simulations, engineering tests have achieved good results in practical projects [1-9]. However, prototype tests are not recommended because of being dangerous and consuming many resources. With the rapid development of computational fluid dynamics (CFD), three-dimensional (3D) CFD simulation becomes a powerful tool to solve turbine flow and unstable problems [13]. Čarija et al. [14] and Drtina et al. [15] validated the accuracy of CFD simulations of Kaplan turbines and found that the differences between the simulations and measurements are almost negligible. Liu et al. [16] used CFD to study the steady operating conditions of a Kaplan turbine and compared the numerical results with experimental data. Regarding transient process simulations by CFD, Liu et al. [17] simulated the runaway transient process of a Kaplan turbine, Yang et al. [18] simulated the load rejection transient process of a bulb tubular turbine, and Chen et al. [19] simulated the load rejection transient process of a Kaplan turbine while considering the double regulations. These works tell us that 3D CFD is reliable and it can be applied to studying turbine transient processes.

The RLU phenomenon with a fixed-blade Kaplan turbine during load rejection transient process was simulated while using the latest 3D CFD in this study to reveal the mechanism of RLUs and find proper solutions. We attributed the reason of the short-term uprush of axial water force to the downstream pumping effect by investigating into the varying trends of macro parameters and detailed flow patterns. Based on the mechanism, we proposed and verified a specific designed piecewise closing rule to solve the RLU problem. The detailed methods, discussions, and verifications will be presented in the following sections. 


\section{Numerical Simulation Conditions}

\subsection{Geometry and Mesh}

An under-construction low-head hydropower station with two $1250 \mathrm{~kW}$ units and one $400 \mathrm{~kW}$ unit was considered. Each unit has its own waterway. One of the $1250 \mathrm{~kW}$ units was chosen as the subject of this study. As shown in Figure 1, the water system includes an upper reservoir (water level $88.00 \mathrm{~m}$ ), a penstock (length $35.0 \mathrm{~m}$, average diameter $2.5 \mathrm{~m}$ ), a fixed-blade Kaplan turbine unit (rated-head $11.13 \mathrm{~m}$, rated discharge $13.8 \mathrm{~m}^{3} / \mathrm{s}$ ), a tailrace tunnel (length $10.6 \mathrm{~m}$, average cross-section $9.6 \mathrm{~m}^{2}$ ), and downstream (water level $74.91 \mathrm{~m}$ ). Table 1 lists the detailed specifications of the Kaplan turbine, where $D_{1}$ is the diameter of the runner, $n_{\mathrm{r}}$ is the rated rotational speed, $W$ is the total weight of rotating parts (including the Kaplan turbine and generator rotor), $W_{\mathrm{a}}$ is the wrap angle of spiral-casing, $z_{\mathrm{b}}, n_{\mathrm{sv}}$, and $n_{\mathrm{gv}}$ are the numbers of runner blades, stay-vanes, and guide-vanes, respectively. In this study, the starting operation point that is shown in Figure 2 with a red square point is the rated point; all of the parameters are the same as the rated parameters.

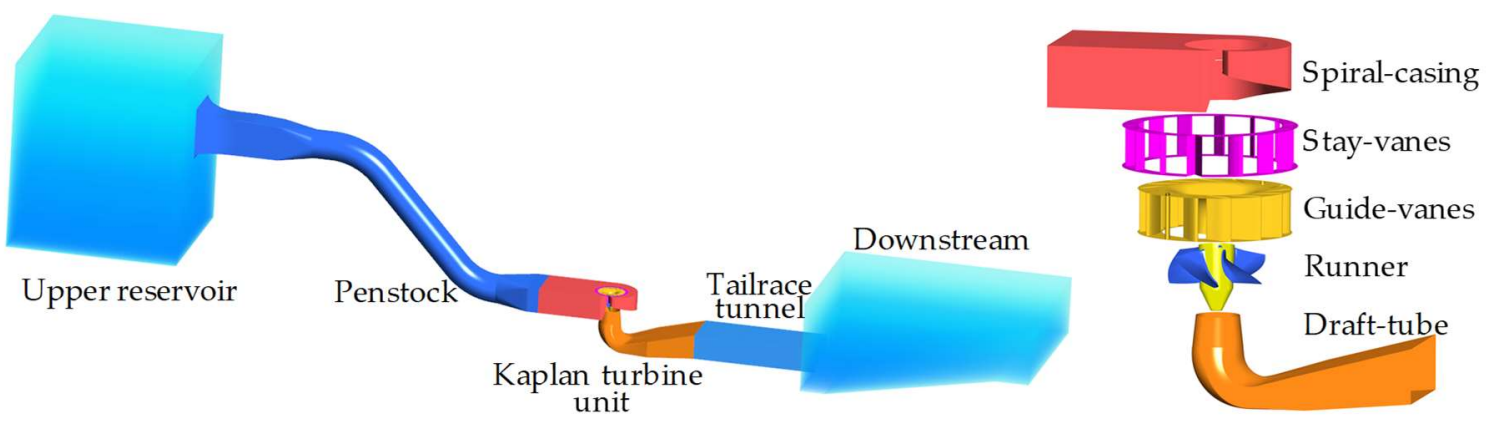

Figure 1. Three-dimensional (3D) computational domains of the waterway and Kaplan turbine unit.

Table 1. Parameters of the Kaplan turbine.

\begin{tabular}{ccccccc}
\hline$D_{\mathbf{1}}(\mathbf{m})$ & $n_{\mathrm{r}}(\mathbf{r p m})$ & $W(\mathbf{k N})$ & $W_{\mathbf{a}}(\mathbf{d e g})$ & $z_{\mathrm{b}}$ & $n_{\mathbf{s v}}$ & $n_{\mathbf{g v}}$ \\
\hline 1.6 & 250 & 140 & 180 & 5 & 14 & 14 \\
\hline
\end{tabular}

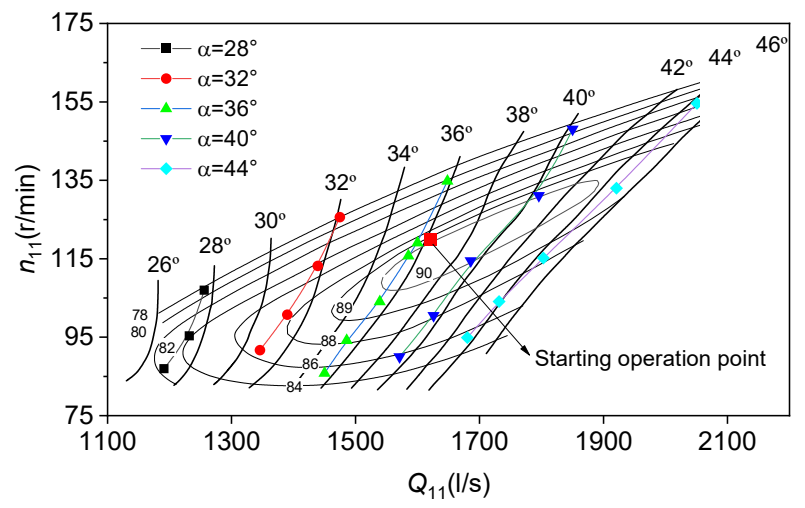

Figure 2. Comparisons between the simulated results and measured characteristic curves. $n_{11}=n \cdot D_{1} / \sqrt{\mathrm{H}} ; \mathrm{Q}_{11}=\mathrm{Q} /\left(D_{1}^{2} \cdot \sqrt{\mathrm{H}}\right)$.

Hybrid mesh was generated while using software ANSYS ICEM 17.0 (ANSYS, Canonsburg, PA, USA) in different domains: wedge mesh in guide-vanes domain and hexahedral mesh in the rest domains (upper reservoir, penstock, spiral-casing, stay-vanes, vaneless space, runner, draft-tube, tailrace tunnel, and downstream). The hexahedral grids at the leading and trailing edge of the runner are locally refined, as shown in Figure 3. 

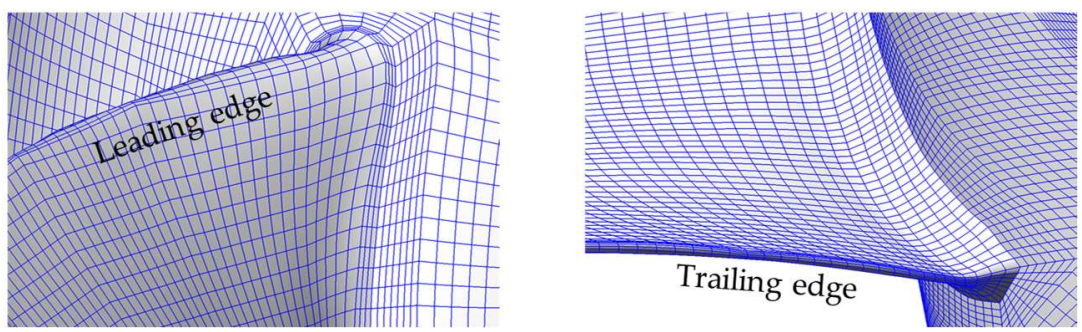

Figure 3. Hexahedral grids around the runner.

Grids independence tests were conducted with four grid refinement levels (3.89 million, 4.27 million, 4.86 million, and 6.20 million) for the starting operating point of this transient simulation. Figure $4 \mathrm{a}$ shows the results of grids independence tests, when the number of grids is more than 5.0 million, the differences of macro-parameters, such as the discharge and moment, are smaller than $0.5 \%$ between the different levels, and the parameters match the rated parameters of the turbine. The tests shows that the simulation while using such mesh can give reasonable results [20]. Besides, the grids independence tests for the transient process were conducted, the three tests showed a similar trend, and the differences between 5.11 million and 6.20 million were very small (Figure $4 \mathrm{~b}$ ). The total grid number was finally chosen as 5.11 million to ensure the balance of simulation accuracy and computer resources. Table 2 shows the specific grids numbers for different domains.

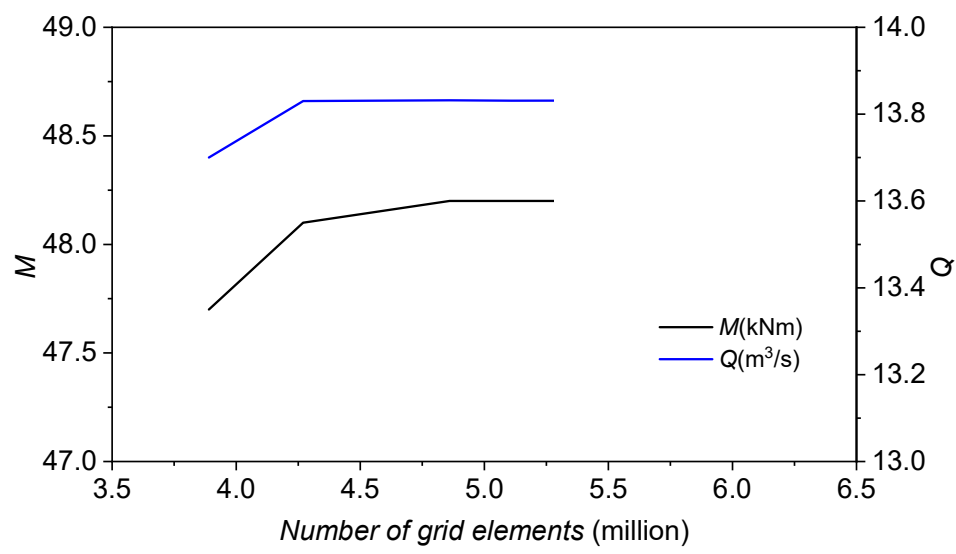

(a)

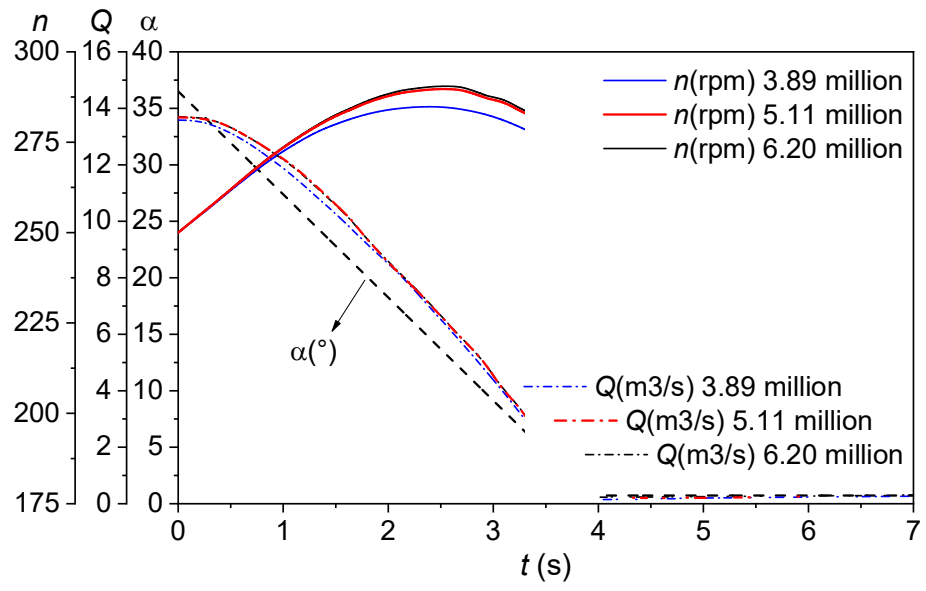

(b)

Figure 4. (a) The results of grids independency tests; (b) The results of grids independence tests for the transient process. 
Table 2. Number of grid elements $\left(\times 10^{4}\right)$.

\begin{tabular}{cccccccc}
\hline $\begin{array}{c}\text { Upper Reservoir \& } \\
\text { Penstock }\end{array}$ & Spiral-Casing & Stay-Vanes & Guide-Vanes & Vaneless Space & Runner & Draft-Tube & $\begin{array}{c}\text { Tailrace Tunnel } \\
\text { \& Downstream }\end{array}$ \\
\hline 117.8 & 19.7 & 32.7 & 54.6 & 29.6 & 74.4 & 149.3 & 32.4 \\
\hline
\end{tabular}

\subsection{Numerical Settings}

The simulations were conducted while using ANSYS FLUENT 17.0. The settings and specific treatments are as follows.

(1) Boundary conditions. The boundary conditions were set according to the actual situations. The reservoirs are treated as the inlet and outlet of the simulation model, in which the atmospheric pressure of $101325 \mathrm{~Pa}$ was specified on the water surfaces and static pressure distributions were specified on the surrounding boundaries. Other walls in the waterway were treated as the non-slip wall.

(2) Water liquid parameters. In the simulation, the material was set as pure water, and the parameters are shown in Table 3.

Table 3. Water liquid parameters.

\begin{tabular}{ccc}
\hline Static Surface Pressure (Pa) & Density $\left(\mathbf{k g} / \mathbf{m}^{\mathbf{3}}\right)$ & Viscosity $(\mathbf{K g} / \mathbf{m} \cdot \mathbf{s})$ \\
\hline 101,325 & 998.2 & 0.001003 \\
\hline
\end{tabular}

(3) Runner rotation government. The sliding mesh model was used in the runner domain. The speed of the runner domain was set as constant $250 \mathrm{rpm}$ in the steady state simulation before load rejection. During load rejection transients, the rotational speed will increase and decrease, which was defined according to Equation (1), where $M$ is the driving moment of turbine, $M_{\mathrm{g}}$ is the retarding moment of generator (becomes zero when load is rejected), $J$ is the rotary inertia of unit, $\omega$ is the angular speed of runner, and $t$ is time. The direction of moment and rotation is determined by the Right-Hand Grip Rule and the vertical downward direction is the positive direction.

$$
M-M_{g}=J \cdot \frac{\omega_{t+1}-\omega_{t}}{\Delta t}
$$

The present time value of $M$ was computed by the function of Fluent (implemented by User Defined Function, UDF) and was used to define the rotational speed of next time.

(4) Guide-vane movement. The wedge mesh in the guide-vanes domain was set as dynamic mesh and the rotating center and axis of each guide-vane was given. During the closure of the guide-vanes, all of them rotated from the 36 degree to 0.73 degree. The guide-vanes cannot be completely closed to 0 degree due to the limitation of dynamic mesh method. The discharge at 0.73 degree is very small, and the guide-vanes can be regarded as completely closed [21,22]). Figure 5 shows the movement of guide-vanes at different time with linear guide-vanes closing rule in the transient process. At $t=0.0 \mathrm{~s}$, the guide-vane opening was 36 degree at the rated opening, under the government of UDF and dynamic mesh method, the guide-vanes rotated to close and the wedge mesh rebuilt, at the end of the guide-vane moment $(t=4.0 \mathrm{~s})$, the guide-vane opening stop at 0.73 degree.

(5) Turbulence model and simulation settings. The $k-\omega$ SST two equation turbulence model was selected. The wall function approach and low-Reynolds number model are the two approaches to model flow near the wall. For the prototype turbine in this study, it is impossible to make $y^{+}=1$ because the Reynolds number is very high; in order to ensure the accuracy of the $k-\omega \mathrm{SST}$, two equation turbulence model, the $y^{+}$value was more than 30 in the whole domain, so that the wall function approach can be used in the simulation. The timestep was set to $0.001 \mathrm{~s}$, which corresponds to 1.5 degrees of runner rotation at the rated speed [20-22]. The SIMPLEC scheme was used in pressure-velocity coupling. In spatial discretization, the gradient was set as Least Squares Cell Based. Pressure standard, momentum, turbulent kinetic energy, and specific dissipation rate were all set as the First Order 
Upwind. In the transient simulation, the residuals of continuity, velocities, $k$ and $\omega$ at each timestep were $1 \times 10^{-5}$, and the maximum iteration number of each timestep was set to 50 .
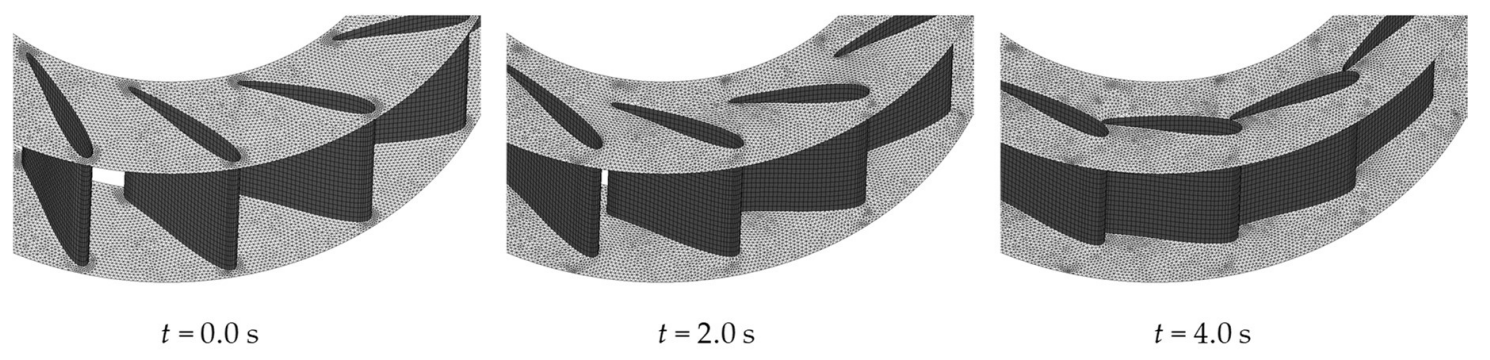

Figure 5. Movement of guide-vanes with dynamic mesh method.

\subsection{Accuracy Validation}

We used the CFD model to simulate 23 static operating points at five different openings and compared them with the characteristic curves measured in model tests of the manufacturer to validate the reliability of the simulation. Figure 2 shows the comparison, in which $Q_{11}$ and $n_{11}$ are the unit discharge and unit speed, respectively. We found that the results of the simulated points agree with the measured curves quite well, with the relative error near the rated operating point being smaller than $2 \%$. The relative errors for the operating regions far from the rated operating point become larger, but the largest one is smaller than $5 \%$.

\subsection{Layout of Monitoring Points}

The monitoring points (P1, P2) were arranged ahead and behind the guide-vanes in the middle span of guide-vane domain to detect the pressure fluctuation histories during the guide-vane closing process, as shown in Figure 6. Monitoring points P3, P4, P5, and P6 were also set to monitor the pressure fluctuations around the runner and to supervise the occurrence of water column separation.


Figure 6. Layout of monitoring points.

\section{Load Rejection Transients with Linear Guide-Vanes Closing Rule}

When load rejection is detected, the governor will drive the guide-vanes to close following a given rule. During the closing process, water hammer waves will be generated due to discharge decrease, with positive value ahead of the guide-vanes and the negative value behind them. The rotational speed will increase first due to the absence of the resistance moment $M_{\mathrm{g}}$, and then decrease due to the decrease and sign reversing of the driving moment $M$ from negative to positive, as in Equation (1). The phenomena composed of load rejection action, guide-vane closure, discharge 
decrease, water hammer generation, transmission and reflection, and speed increase and decrease, are generally called the load rejection transients.

We first simulated the load rejection transients with a linear guide-vane closing rule in this study.

\subsection{Variations of Macro Parameters}

We obtained the macro parameters from the 3D CFD simulation, given the linear closing time of guide-vanes $T_{\mathrm{s}}=4.0 \mathrm{~s}$, and Figure 7 shows the history curves of the key parameters. When the guide-vane opening $\alpha$ changes from 36 degree to 0.73 degree linearly, the discharge decreases from $13.8 \mathrm{~m}^{3} / \mathrm{s}$ to $0.2 \mathrm{~m}^{3} / \mathrm{s}$ with first slow and then fast rate. The rotational speed $n$ increases during $t=0 \mathrm{~s}$ to $2.52 \mathrm{~s}$ and then decreases. The maximum rotational speed reaches $289.7 \mathrm{rpm}$ at $t_{\mathrm{nmax}}=2.52 \mathrm{~s}$, with a maximum speed rise ratio of $15.88 \%$. After $t_{\mathrm{nmax}}=2.52 \mathrm{~s}$ the turbine enters the turbine braking mode, in which the moment becomes positive, which leads to the decrease of speed. During the whole process, the axial water force on the runner $F_{z}$ experiences great fluctuations. At the beginning of load rejection, $F_{\mathrm{z}}$ is negative (vertically downward) with a value of $-79.4 \mathrm{kN}$. $F_{\mathrm{Z}}$ increases and it changes from negative to positive at $t=2.13 \mathrm{~s}$. The continuous increase of $F_{\mathrm{Z}}$ is accompanied by the increase of rotational speed $n$ and the decrease of discharge. $F_{z}$ still increases for a short period after the guide-vane closing stops at $t=3.92 \mathrm{~s}$ ( 0.73 degree opening). At $t=4.04 \mathrm{~s}, F_{\mathrm{z}}$ reaches at its maximum $195.8 \mathrm{kN}$, which exceeds the unit's weight $W=140 \mathrm{kN}$ by $39.9 \%$. The period of the upward axial water force being larger than the weight of the rotating parts is from $t_{1(\mathrm{Fz}>\mathrm{W})}=3.57 \mathrm{~s}$ to $\left.t_{2(F z}>W\right)=6.13 \mathrm{~s}$, yielding the unbalance time $\left.T_{F}>W=t_{2(F z}>W\right)-t_{1(F z>W)}=2.56 \mathrm{~s}$. It is known from the authors' experience that this time is enough for a RLU accident.

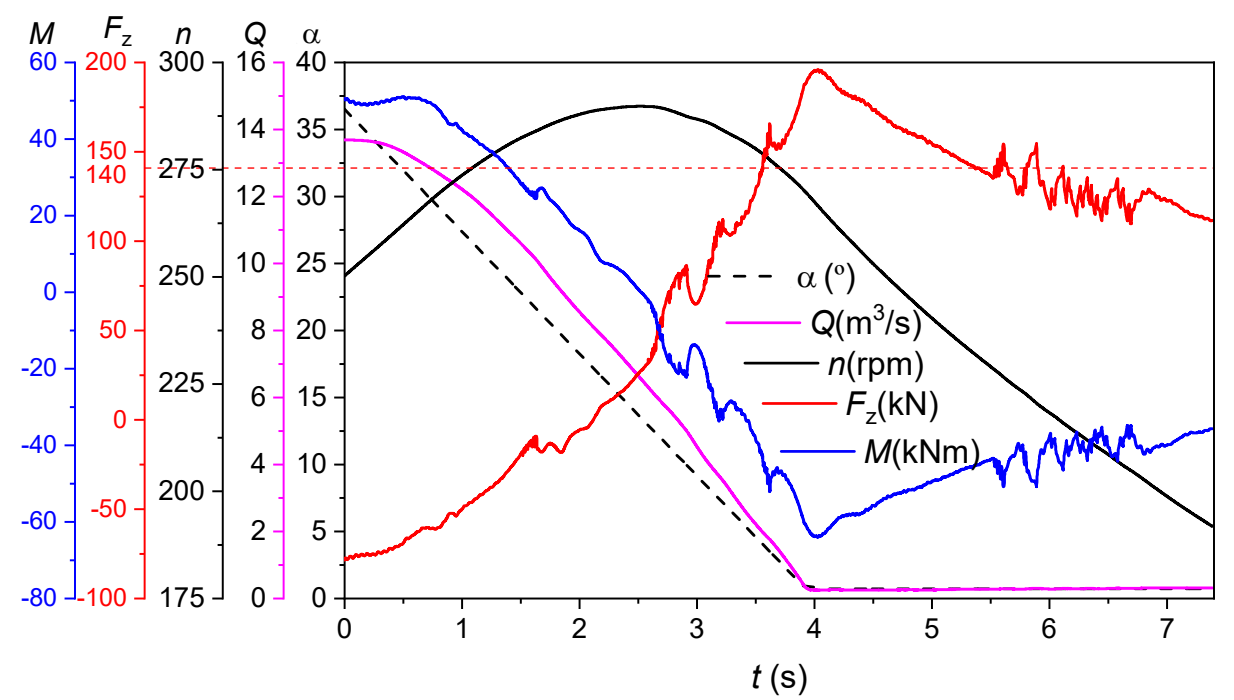

Figure 7. Variations of macro-parameters during load rejection with linear closing rule. $\alpha$ : Opening of guide-vanes; $Q$ : Discharge; $n$ : Rational speed; $F_{Z}$ : Upward axial force; and, $M$ : Moment of runner.

\subsection{Variations of Pressures at Monitoring Points}

Figure 8 shows the pressure fluctuation histories at P1, P2, $\ldots$, and P6. During the process of guide-vane closure, the pressure at $\mathrm{P} 1$ increases gradually, while the pressures at $\mathrm{P} 2$ and $\mathrm{P} 3$ gradually decrease, indicating water hammer characteristics. The pressure rise ratio at $\mathrm{P} 1$ is $39.18 \%$, matching the requirement of less than $50 \%$ in Design code for small hydropower station in China [23]. The pressure at P3 drops to its minimum $-66.68 \mathrm{kPa}$, which is consistent with the results of reference [24]. When compared with the vaporization pressure value of $-99.659 \mathrm{kPa}$ at room temperature, there is a safety margin of $32.98 \mathrm{kPa}$, so no water column separation occurs during the load rejection process. The pressure at these points is greatly affected by the runner blades because P3 is near the inlet of runner blades, while P4 and P5 are near the outlet of runner blades (Figure 6). The high-frequency pressure pulsations 
at P3, P4 and P5 are displayed in Figure 8, which is consistent with the blades passing frequency of the runner. The reason of strong pulsations at $\mathrm{P} 4$ is because its location close to the draft-tube wall, where the blades interact with the wall with high rotational speed [25]. The low-frequency components in the curves are the signs of the draft-tube vortices and they will be discussed later. After guide-vane closing is finished, the average pressure at $\mathrm{P} 4$ becomes obvious higher than those at $\mathrm{P} 5$ and $\mathrm{P} 6$, reflecting that they are the main regions of the pumping effect.

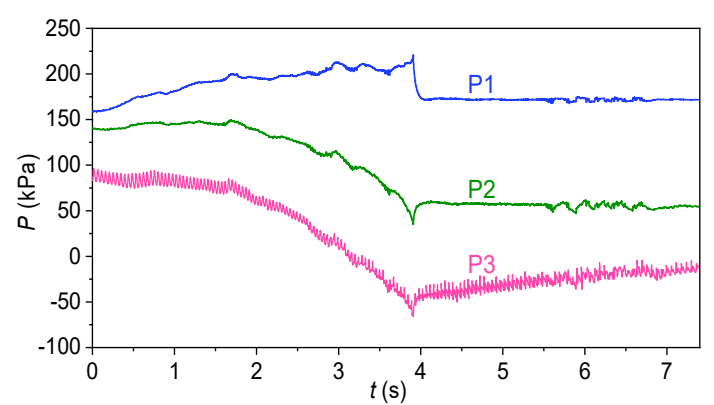

(a)

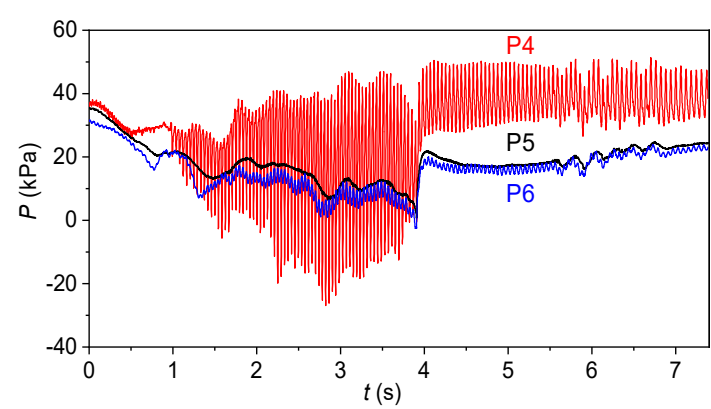

(b)

Figure 8. Pressure histories of monitoring points during the transient process. (a) P1: Point before guide-vanes; P2: Point after guide-vanes; P3: Point before runner blades. (b) P4: Point near wall of draft-tube; P5: Point in center of draft-tube; and, P6: Point under the runner hub.

\section{Mechanism Analysis of RLU}

\subsection{Variation of Forces on Runner}

The red curve in Figure 7 is the history curve of the axial water force on the runner, $F_{\mathrm{z}}$, which is the integrated force on the whole runner. The forces that are generated by the blades are the dominant part. Four typical time instants in the process of the load rejection are selected to analyze the force characteristics on blades. The instants $t=0.00 \mathrm{~s}, 2.12 \mathrm{~s}, 2.52 \mathrm{~s}$, and $4.04 \mathrm{~s}$ are corresponding to the beginning of the process, the zero axial force time, the time of maximum rotational speed $\left(t_{\mathrm{nmax}}\right)$, and the maximum axial force time, respectively. Figure 9 shows the pressure distributions on blade surfaces and the decomposed forces, in which, $F_{\theta}$ and $F_{\theta}^{\prime}$ stand for the horizontal circumferential tangential force that is generated on the pressure side and the suction side, respectively; $F_{A}$ and $F_{A}^{\prime}$ stand for the axial downward force that is generated on the pressure side and the suction side, respectively.

At $t=0.00 \mathrm{~s}$, the discharge of turbine is at its rated, the overall pressures on the pressure side are greater than those on the suction side, and the total axial force on the runner is negative. With the closing of guide-vanes, the discharge gradually decreases, and the pressures on the pressure side decrease, leading to the decrease of $F_{A}$. As the discharge decreases, the effect of upward force become stronger, the pressure on suction side increases gradually, so the $F_{A}^{\prime}$ increases. The $F_{A}$ decreases and the $F_{A}^{\prime}$ increases directly cause the axial force to turn from negative to positive. When the discharge decreases, the water force on the runner turns from negative to positive, which is why the $F_{\theta}$ decreases and $F_{\theta}^{\prime}$ increases. As a result, the moment of runner turns from output to input.

The downstream pumping effect is produced due to blades begin to propel water downstream when the rotational speed reaches the maximum at $t=2.52 \mathrm{~s}$ in the processes of speed increase and discharge decrease. After that, the runner begins to work in braking mode, in which the rotating kinetic energy of the runner is consumed and the speed decreases. The runner pumps the water downstream, and water reaction forces make the axial force $F_{z}$ more rapidly increase. When the discharge approaches to zero, the downstream pumping effect becomes strong and $F_{\mathrm{Z}}$ reaches it summit at $t=4.04 \mathrm{~s}$. The high pressure regions on the blade suction side concentrate to the blade tips $(t=3.56 \mathrm{~s}$ and $4.04 \mathrm{~s}$ ), while the low pressure regions on the blade pressure side become apparent in the root regions because of the strong propelling and centrifugal effects. 


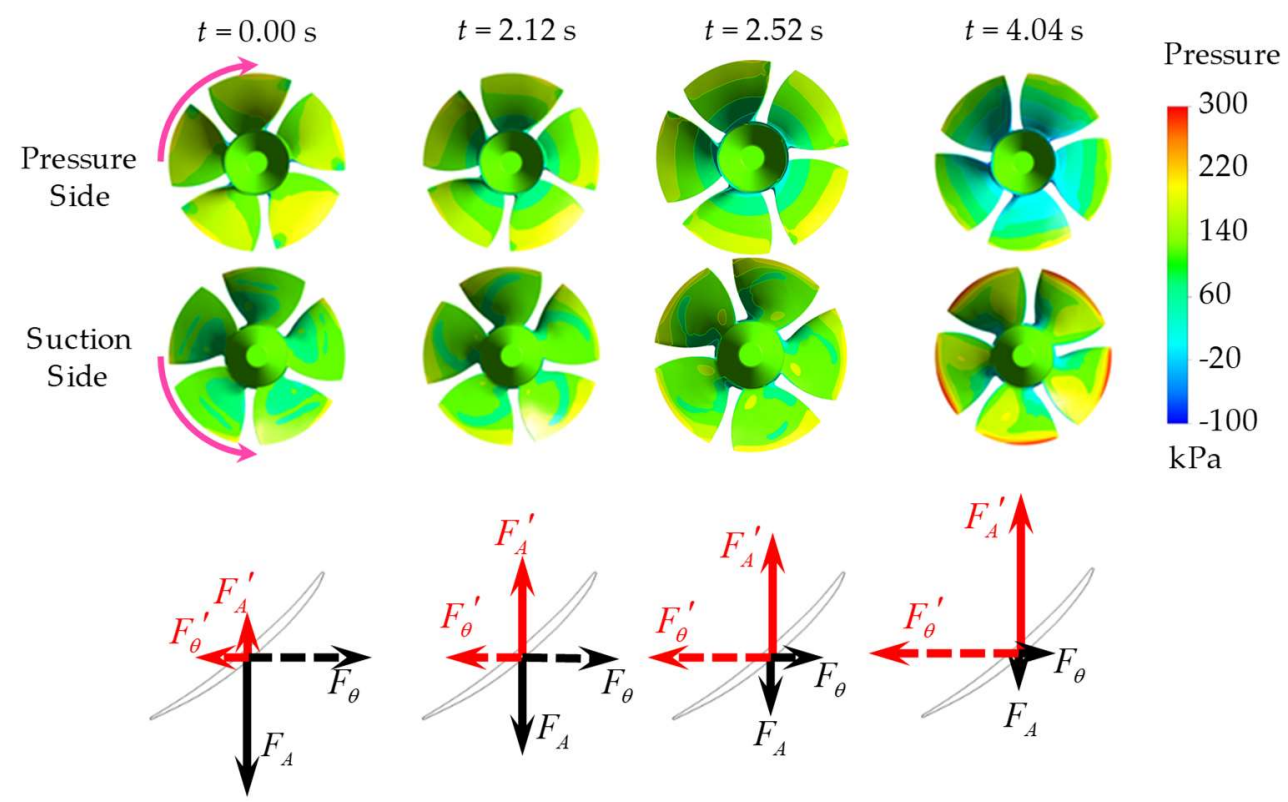

Figure 9. Variation of forces on runner.

\subsection{Variation of Flow Patterns in Runner and Draft-Tube}

During the load rejection transients, the vortices inside the runner mainly cause turbine energy dissipation. The $\mathrm{Q}$ criterion with level value of 0.08 is used to monitor the vortex patterns in the runner region, as shown in Figure 10.
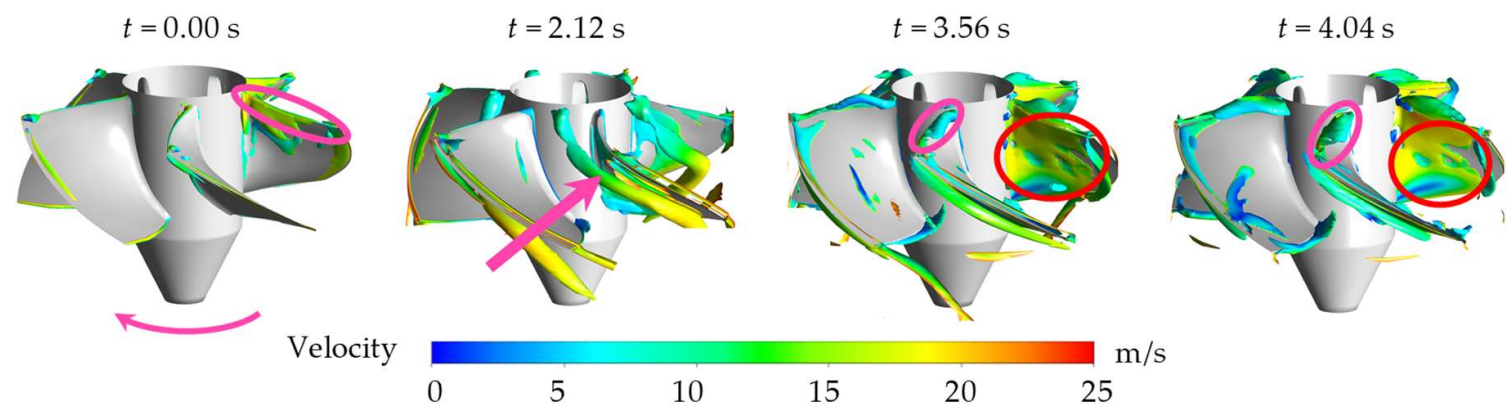

Figure 10. Variation of vortex structure in the runner displayed by $Q$ criterion.

When the load is just rejected at $t=0.00 \mathrm{~s}$, the turbine is in a high efficiency operating point, showing smooth flow patterns. Small striking vortices are generated near the inlet of blade suction side because the attack angle at the runner inlet is not the best angle (Figure 10). At the runner outlet, the flow is vertical with no rotational component, and the flow in draft-tube region is smooth (Figure 11).

At $t=2.12 \mathrm{~s}$, discharge is reduced to $59.2 \%$ of the rated value, and the runner moment approaches zero. A large number of tubular vortices are generated in the runner (indicated by the pink arrow, Figure 10), which gather to the blade tips, indicating the increase of resistant moment. Under the influence of the runner, the flow in the center region of draft-tube goes up and rotates with a smaller velocity (indicated by the red arrow, Figure 11), while the flow near the wall region goes down and then rotates with a higher velocity (indicated by the blue arrow, Figure 11). The rotational directions of the flows are the same as that of the runner (Figure 11).

At $t=3.56 \mathrm{~s}$, the discharge decreases to $14.4 \%$ of the rated value, and the axial force on the runner becomes larger than the weight of the rotating parts of unit $\left(F_{\mathrm{z}}>W\right)$, which indicates a possibility of RLU. The tubular vortices are obviously smaller than those at $t=2.12 \mathrm{~s}$ because of lower 
discharge. The planar vortices totally cover the suction side of blades (indicated by the red circle, Figure 10), and emerge some vortices at the leading edge (indicated by the pink circle, Figure 10). The planar vortices on the suction side and the vortices at leading edge indicate that the resistant moment become stronger.


Velocity

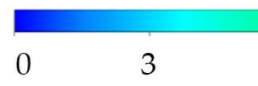

6

12 15

Figure 11. Variation of flow patterns in draft-tube (in order to show the flow patterns clearly, a gray plane was set in the draft-tube).

At $t=4.04 \mathrm{~s}$, the guide-vanes are completely closed, and the discharge approaches to zero. The vortices continue to increase, especially at the inlet edges of the runner (Figure 10). At this time, the rotational speed decreases to $105 \%$ of the rated value. The flow velocity in the draft-tube decreases due to the decrease of rotational speed; however, the flow rotation in the draft-tube is stronger than that at $t=3.56 \mathrm{~s}$, because the rotating kinetic energy of the runner convers to the rotating kinetic energy of water (Figure 11).

The pumping effect is the fundamental reason for the increase of axial force $F_{\mathrm{z}}$, which is related to the complex flow patterns in the draft-tube. Figure 12 shows the pressure distribution on Span $0.1,0.5$, and 0.9 of the runner. From Span 0.1 to Span 0.9, the blade inclination changes from steep to gentle because of the geometric structure of Kaplan turbine. The steep blade angle can lead to large resistance, while the gentle blade angle can lead to a strong pump effect. That is why the pressure and velocity on Span 0.1 are smaller than those of Span 0.9. These pressure and velocity distributions, along with the small discharge, make the flow patterns under the runner demonstrate center-upward surrounding-downward recirculating characteristics (Figure 11).

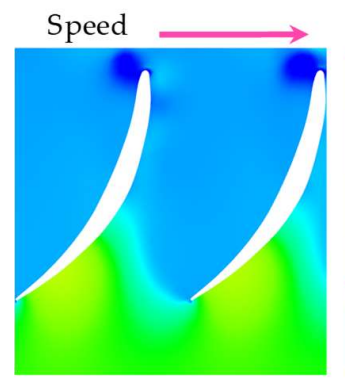

Span 0.1



Span 0.5



Span 0.9

Pressure $-100$ $-50$

0 $50 \quad 100$ $\mathrm{kPa}$

Figure 12. Pressure contour in the runner on different span sections.

\subsection{Mechanism of RLU}

We might describe the mechanism of RLU while synthesizing the rules in macro parameters, flow patterns, and pressure distribution, as follows. During the load rejection transients, with the closing of guide-vanes, the discharge of turbine decreases, and the rotational speed rises first and 
then decreases. The runner will enter the downstream pumping mode, in which the runner propels water downstream, because of the low discharge and high speed. The pressure on the pressure side of runner blades become lower, while the pressure on the suction side become higher, which produces a larger upward axial force $F_{\mathrm{z}}$. $F_{\mathrm{z}}$ rapidly increases as discharge decreases sharply to a very low value or even to zero. The RLU might occur if $F_{Z}$ exceeds the weight of rotating parts $W$. The maximal $F_{\mathrm{Z}}$ happens after discharge approaches to zero, because the pumping effect becomes larger with smallest discharge and relative higher speed. After the summit, $F_{Z}$ decreases as the speed falls. When speed falls to a certain value, $F_{\mathrm{Z}}$ will become smaller than $W$, which indicates the ending of RLU. The simultaneous occurrence of low discharge and high speed is the reason of the pumping effect, which is also the reason for RLU. In the downstream pumping mode, the flow in the draft-tube demonstrates center-upward surrounding-downward recirculating characteristics, and the vortices in the runner shows complex structures.

\section{Solution to the RLU Problem}

\subsection{Basic Idea on the Solution}

Adjusting guide-vane closing rule is always the first considered means to solve the guarantee regulation problems in load rejection transients of hydropower stations. Trying to reduce the axial water force $F_{\mathrm{z}}$, we first adjust only the closing time $T_{\mathrm{s}}$, and found that $F_{\mathrm{z}}$ cannot be reduced apparently when using a linear rule, no matter shortening or lengthening $T_{\mathrm{s}}$. This is because the simultaneous occurrence of low discharge and high speed cannot be avoided. Even the rated speed meeting a zero discharge will generate a $F_{z}$ that may cause RLU.

We proposed to suspend the closing after $t_{\mathrm{nmax}}=2.52 \mathrm{~s}$ for a certain period to reduce the speed by making use of the braking effect when considering the mechanism of large $F_{z}$, and knowing that the turbine is working in the braking mode after the maximum speed time $t_{\text {nmax }}=2.52 \mathrm{~s}$ (Figure 7). If the suspending opening and time are proper, the speed can be reduced to a value that restrains the pumping effect to generate larger $F_{\mathrm{z}}$. When $F_{\mathrm{z}}$ is kept low, the suspended closing can then be continued until final closed.

This is a piecewise closing rule that can avoid the simultaneous occurrence of high speed and low discharge. The suspending period in the middle reach of the closing rule can reduce the speed and make the zero discharge time $t_{\mathrm{Qmin}}$ far lag behind the maximum speed time $t_{\mathrm{nmax}}$.

The proper selections of the starting instant of suspending, the suspending opening, and the suspending period are the keys to for using the above piecewise closing rule. The starting instant of suspending should be in between the maximum speed instant $t_{\mathrm{nmax}}$ and the instant $t_{1(\mathrm{Fz}>W)}$ when $F_{\mathrm{z}}>W$ first happens. The closer to $t_{1(F \mathrm{z}>W)}$ the faster the speed decreases. However, if we chose $\left.t_{1(F z}>W\right)$ as the starting instant of suspending, the risk of RLU might exist. Therefore, a margin should be left. When the starting instant is set, we will then know the corresponding opening by following the original linear closing rule. The suspending might be ended when the reduced speed is smaller than the speed value at $t_{2(F z>W)}$ when $F_{z}>W$ ends; therefore, the suspending period is certainly larger than the period of $F_{\mathrm{Z}}>W$. The suspending period can be determined by trial and error simulations, and it should be extended to further reduce the speed to a lower value for safety margin.

\subsection{Feasibility Verification with the Piecewise Closing Rule}

For the $T_{\mathrm{s}}=4.0 \mathrm{~s}$ linear closing rule in Figure $7, t_{\mathrm{nmax}}=2.5 \mathrm{~s}, t_{1(\mathrm{Fz}>W)}=3.57 \mathrm{~s}$ and $\left.t_{2(F \mathrm{z}}>\mathrm{W}\right)=6.13 \mathrm{~s}$. We made several trial and error simulations and selected a proper piecewise rule, with the starting instant $t=3.2 \mathrm{~s}$, the suspending period $5.0 \mathrm{~s}$, and the total closing time $T_{\mathrm{s}}=9.0 \mathrm{~s}$, as shown in Figure 13 .

The macro-parameter histories from $0.0 \mathrm{~s}$ to $3.2 \mathrm{~s}$ are consistent with those for the original closing rule depicted in Figure 7. After the guide-vane opening is suspended at $t=3.2 \mathrm{~s}$, the discharge $Q$ first has a slight disturbance and then keeps stable at around $2.96 \mathrm{~m}^{3} / \mathrm{s}$. The axial water force $F_{\mathrm{Z}}$ continues to rise first and then gradually falls, with the highest value $139.2 \mathrm{kN}$ at $t=3.66 \mathrm{~s}$, nearly touching 
the $W$ line. The rotational speed $n$ continually decreases from $285.1 \mathrm{rpm}$ at $t=3.2 \mathrm{~s}$ to $229.7 \mathrm{rpm}$ at $t=8.2 \mathrm{~s}$. The suspension stops at $t=8.2 \mathrm{~s}$, and then guide-vanes close linearly to zero within $0.72 \mathrm{~s}$. This second rapid closing makes $Q$ and $n$ decrease sharply, which results in the rebounding of $F_{z}$. $F_{\mathrm{z}}$ goes up again until reaching at $138.7 \mathrm{kN}$ at $t=9.43 \mathrm{~s}$, and then gradually goes down. Under this piecewise closing rule, $F_{z}>W$ is prevented; therefore, the RLU possibility is eliminated. The machine manufacturer has accepted this newly proposed guide-vane closing rule, and it will be implemented in the practical project.

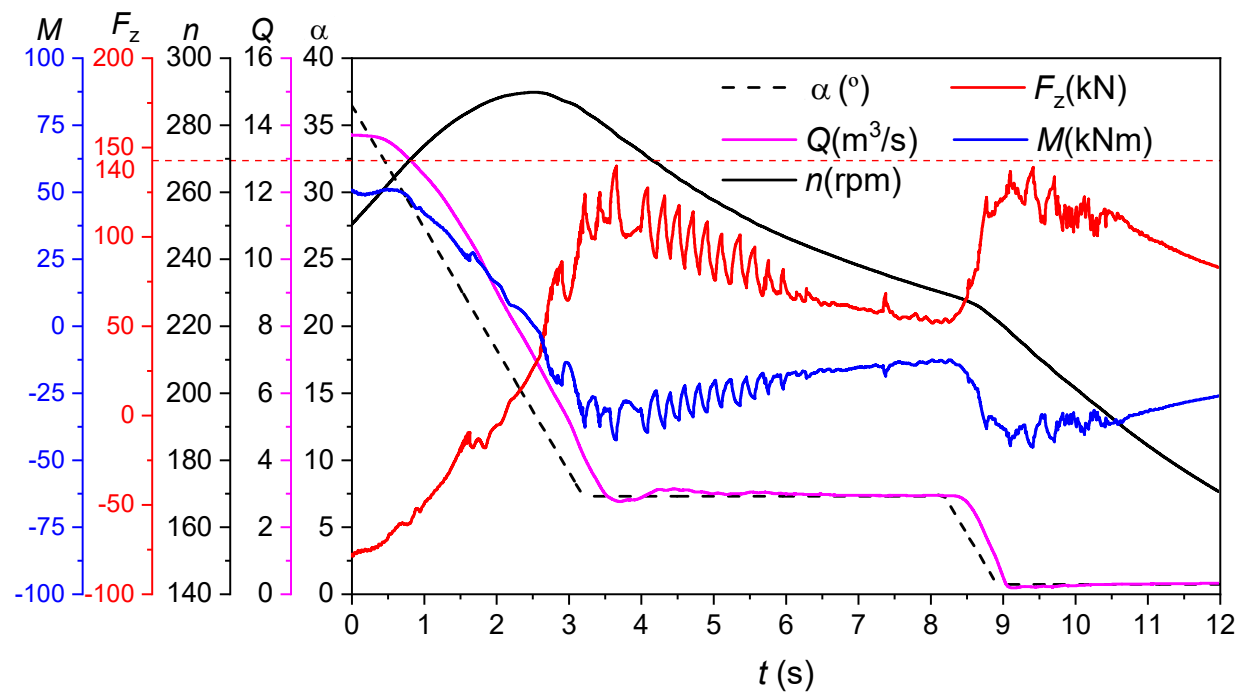

Figure 13. Variation of macro-parameters during load rejection transients under a piecewise closing rule. $\alpha$ Opening of guide-vanes; $Q$ Discharge; $n$ Rational speed; $F_{Z}$ Upward axial force; M Moment of runner.

\subsection{Fluctuation Reasons in the History Curves of Axial Force}

While investigating the curves of $F_{\mathrm{Z}}$ and $M$ in Figures 7 and 13, we found that these two parameters have similar changing features, which is normal because they are the two components of the force on runner blades (Figure 9). Nevertheless, as an unusual feature, the saw-tooth fluctuations on the generally smooth curves are also obvious. The fluctuations appear during $2.91 \mathrm{~s}$ to $3.73 \mathrm{~s}$ and $5.61 \mathrm{~s}$ to $6.85 \mathrm{~s}$ for the $4.0 \mathrm{~s}$ linear closing rule, and during $2.91 \mathrm{~s}$ to $6.14 \mathrm{~s}$ and $8.79 \mathrm{~s}$ to $10.55 \mathrm{~s}$ for the $9.0 \mathrm{~s}$ closing rule. The occurrence of these fluctuations is coincident with the periods when the downstream pumping effect is stronger. We found that the fluctuating frequencies were consistent with the runner rotational frequency around $0.24 \mathrm{~Hz}$.

We choose the fluctuation in $T_{\mathrm{s}}=9.0 \mathrm{~s}$ closing rule for further analysis. We attributed the reason to the fluctuations of the recirculating large vortices between the runner and the draft-tube elbow when considering the recirculating flow in draft-tube and the vortex structure in the runner. The flow vortices in draft-tube are extremely complex. We display two-dimensional 3D vortices on the two-dimensional (2D) central plane of draft-tube for the convenience of analysis (Figure 14). In general, there are three vortices in the draft-tube, one large on the left side of the elbow and two small on the right side of the elbow (Figure 14, $t=4.18 \mathrm{~s}$ ). The three vortices become small at $4.28 \mathrm{~s}$, and then become large at $4.40 \mathrm{~s}$ with the same size as at $4.18 \mathrm{~s}$. From $t=4.18 \mathrm{~s}$ to $t=4.40 \mathrm{~s}$, the vortices complete a period of changes, which is consistent with the fluctuating period.

Figure 15 shows the evidence, at $t=4.18 \mathrm{~s}$, the iso-surface of pressure shifts downstream, the pressure behind the runner decreases, and the $F_{\mathrm{Z}}$ curve is in the trough position (Figure 13). At $t=4.28 \mathrm{~s}$, the iso-surface shifts upstream, the pressure behind the runner increases (Figure 15), and the $F_{\mathrm{z}}$ curve is at the peak position (Figure 13). At $t=4.40 \mathrm{~s}$, the $F_{\mathrm{z}}$ curve comes to another trough position. It is the strong propelling of the runner and the throttling of the elbow that make the 
recirculating vortices inside the draft-tube unstable and pressure fluctuation excited. The fluctuations calm down when the propelling effect decreases. The abrupt increase and decrease of pressure indicate that this fluctuation is connected to some resonance characteristics in the draft-tube.

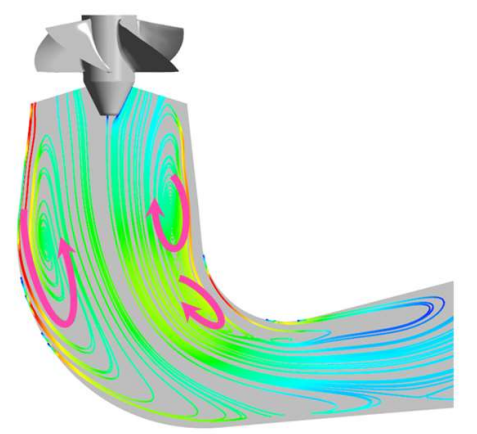

$t=4.18 \mathrm{~s}$

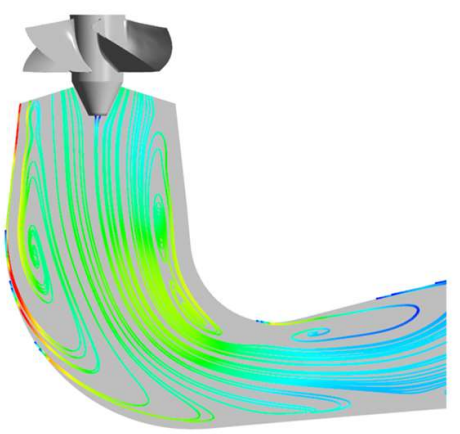

$t=4.28 \mathrm{~s}$

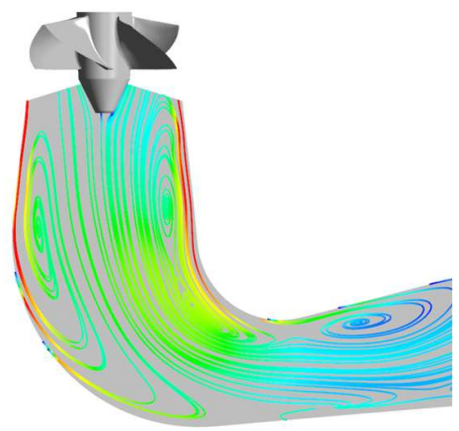

$t=4.40 \mathrm{~s}$

Velocity

0

2.5

5.0

7.5

$\mathrm{m} / \mathrm{s}$

Figure 14. Periodic variation of vortex patterns in the draft-tube.

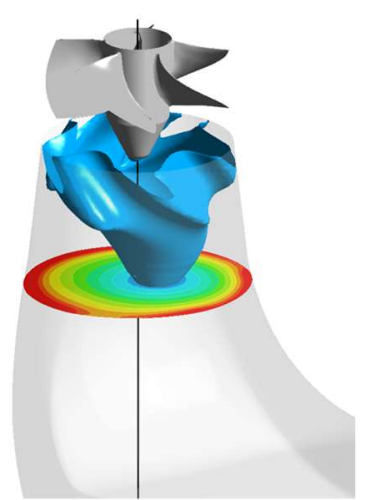

$t=4.18 \mathrm{~s}$

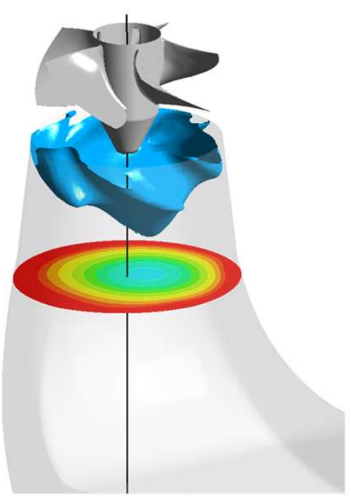

$t=4.28 \mathrm{~s}$



$t=4.40 \mathrm{~s}$

Pressure

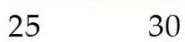

35

40

45

$\mathrm{kPa}$

Figure 15. Periodic pressure fluctuation in the draft-tube. The pressure of the iso-surface is $30 \mathrm{kPa}$; the pressure plane contour is $3 \mathrm{~m}$ below the draft-tube inlet; the black line is the axis of rotation.

\section{Conclusions}

In this study, the runner lifting-up (RLU) problem of a fixed-blade Kaplan turbine during load rejection transient process in a practical hydropower station was investigated by using 3D CFD transient simulations. The mechanism of the upward boosting of the axial water force on the runner was revealed based on evidence in parameter histories and flow structures. We proposed a modified guide-vane closing rule to avoid RLU while understanding the physics. Moreover, this means was successfully verified. The conclusions are as follows:

(1) The RLU problems during the load rejection transients of Kaplan turbines may be caused by two reasons: reverse water hammer and downstream pumping effect. In the case of this study, there is no reverse water hammer, because the smallest pressure at the runner inlet during the guide-vane closing process is always higher than the cavitation pressure. The downstream pumping effect is the cause of the upward boosting of the axial water force on the runner. This axial water force has been larger than the weight of rotating parts of the unit for a certain time, which indicates the possibility of RLU. 
(2) The pumping effect can appear when a high rotational speed meets a low discharge. The guide-vanes begin to close after the load is rejected. During this process, the increase of rotational speed and the decrease of discharge happen simultaneously. The high speed makes the runner strongly propelling water downstream, and the low discharge make the flow in the draft-tube strongly recirculating, flowing downstream near the drat-tube wall and flowing back in the center to balance the overall discharge. The axial water force is the reacting force of the propelling force.

(3) The simultaneous occurrence of high rotational speed and low discharge cannot be avoided by only adjusting the guide-vane closing time. However, one can use a piecewise closing rule that has a suspending period in the middle reach. This opening unchanged period is used to reduce the rotational speed by the braking effect in the turbine-braking mode. A suitable starting instant and duration of the suspending are the keys in decelerating the speed and, hence, controlling the upward axial water force. The effectiveness of the piecewise closing rule is successfully verified.

(4) The above conclusions on the mechanism and solution of RLU are evident for fixed-blade Kaplan turbines, and their validity for adjusting-blade Kaplan turbines should be further studied. One of the main differences that the downstream pumping effect can be kept at a low level by adjusting the blade angle should be focused on.

Author Contributions: Data curation, Z.Y. and Y.Z.; Formal analysis, K.L. and Y.C.; Investigation, F.Y. and Y.Z.; Resources, F.Y.; Validation, Z.Y.; Writing—original draft, K.L.; Writing—review \& editing, K.L. and Y.C.

Funding: This work was supported by the National Natural Science Foundation of China (NSFC) (Grant Nos. 51579187 and 51839008) and the Natural Science Foundation of Hubei Province (Grant No. 2018CFA010).

Acknowledgments: The numerical simulations were conducted on the supercomputing system in the Supercomputing Center of Wuhan University.

Conflicts of Interest: The authors declare no conflict of interest.

\section{References}

1. Pejovic, S.; Gajic, A. The Rules for Hydraulic Transient Design Analysis-Guide for Designers and Manufacturers-Recommendations for Investors and Managers, 1st ed.; Academic Mind: Belgrade, Yugoslavia, 2018; pp. 26-43.

2. Hillgren, N. Analysis of Hydraulic Pressure Transients in the Waterways of Hydropower Stations, 1st ed.; Uppsala Universitet: Uppsala, Sweden, 2011; pp. 19-20.

3. Han, Y.; Liu, Q. Analysis on A Raising-turbine Accident Resulting from Reversion Water Hammer and Precautionary Measures. Guizhou Water Power 1998, 12, 36-37. (In Chinese)

4. Huang, D.; Yuan, B.; Yu, Z. Treatment of Machine Lifting for Kaplan Turbine. Water Resour. Power 2009, 27, 161-162. (In Chinese)

5. Lei, J.; Li, J. Practice and Discussion on Preventing Lifting and Reducing Reverse Water Hammer of Hydraulic Turbine. Mech. Electr. Tech. Hydropower Stn. 2010, 33, 11-15. (In Chinese)

6. Min, J. Cause and prevention method of uplift for Kaplan turbine with variable blade. Mech. Electr. Tech. Hydropower Stn. 2014, 37, 7-10, 87. (In Chinese)

7. Chang, J. A rational control mode for load-rejection transient process of Kaplan turbine installation. J. Hydraul. Eng. 1986, 7, 29-36. (In Chinese)

8. Cai, F.; Ji, S. Cause Analysis of "Lifting-Set" of Propeller Hydraulic Turbines and Their Strategies. China Rural Water Hydropower 1997, 8, 10-13. (In Chinese)

9. Yang, E.; Cheng, B. Brief Analysis of Lifting Phenomenon of Hydraulic Turbine Unit during Load Rejection and Its Preventive Measures. Guizhou Water Power 2006, 20, 48-50. (In Chinese)

10. Simpson, N.R.; Tijsseling, R.S. Water hammer with column separation: A review of research in the twentieth century. Tech. Univ. 2004, 1, 6-19.

11. Zhang, X.; Cheng, Y.; Xia, L.; Yang, J. CFD simulation of reverse water-hammer induced by collapse of draft-tube cavity in a model pump-turbine during runaway process. In IOP Conference Series: Earth and Environmental Science; IOP Publishing: Bristol, UK, 2016; Volume 49, p. 052017.

12. Pejovic, S.; Gajic, A. Water Column Separation at Turbine Start up Loading. In IOP Conference Series: Earth and Environmental Science; IOP Publishing: Bristol, UK, 2019; Volume 240, p. 062044. 
13. Dudlik, A.; Koutnik, J. Water hammer 2 phase analysis hydraulic system with a Kaplan turbine. Kaplan Turbine 2019, 10, 613-624.

14. Čarija, Z.; Mrša, Z.; Dragović, L. Turbulent Flow Simulation in Kaplan Draft Tube. In Proceedings of the 5th International Congress of Croatian Society of Mechanics, Trogir/Split, Croatia, 21-23 September 2006; pp. 21-23.

15. Drtina, P.; Sallaberger, M. Hydraulic turbines-Basic principles and state-of-the-art computational fluid dynamics applications. J. Mech. Eng. Sci. 1999, 213, 85-102. [CrossRef]

16. Liu, S.; Wu, Y.; Jie, S.; Wu, S. Numerical simulation of pressure fluctuation in Kaplan turbine. Sci. China 2008, 51, 1137-1148. [CrossRef]

17. Liu, S.; Zhou, D.; Liu, D.; Wu, Y.; Nishi, M. Runaway transient simulation of a model Kaplan turbine. In IOP Conference Series: Earth and Environmental Science; IOP Publishing: Bristol, UK, 2010; Volume 12, p. 012073.

18. Yang, Z.; Cheng, Y.; Xia, L.; You, J. 3D numerical simulation of load rejection transients of a bulb hydraulic turbine. Eng. J. Wuhan Univ. 2018, 51, 854-860, 875. (In Chinese)

19. Chen, H.; Zhou, D.; Zheng, Y.; Jiang, S.; Yu, A.; Guo, Y. Load Rejection Transient Process Simulation of a Kaplan Turbine Model by Co-Adjusting Guide Vanes and Runner Blades. Energies 2018, 11, 3354. [CrossRef]

20. Xia, L.; Cheng, Y.; Yang, Z.; You, J.; Yang, J.; Qian, Z. Evolutions of Pressure Fluctuations and Runner Loads during Runaway Processes of a Pump-Turbine. J. Fluids Eng. 2017, 139, 091101. [CrossRef]

21. Zhang, X.; Cheng, Y.; Yang, J.; Xia, L.; Lai, X. Simulation of the load rejection transient process of a Francis turbine by using a 1-D-3-D coupling approach. J. Hydrodyn. 2014, 26, 715-724. [CrossRef]

22. Yang, Z.; Cheng, Y.; Fang, C. Three-dimensional CFD simulation of the load rejection transient process considering regulating system. In IOP Conference Series: Earth and Environmental Science; IOP Publishing: Bristol, UK, 2018; Volume 163, p. 012079.

23. China Renewable Energy Engineering Institute; Sichuan Water Resources and Hydroelectric Investigation \& Design Institute. Speed control system and regulation guarantee calculation. In Design Code for Small Hydropower Station; Jihua Press of China: Beijing, China, 2014; p. 39.

24. Liu, Y.; Chang, J. Study on Reverse Water Hammer of the Kaplan Turbine. Adv. Water Resour. Hydraul. Eng. 2009, 1, 2208-2213.

25. Zheng, X.; Luo, X.; Guo, P. Analysis of Pressure Fluctuation in Draft Tube of Kaplan Turbine. Sci. Rep. 2009, 1, 341-344. 